\title{
PRODUKTIVITAS ALAT TANGKAP PANCING ULUR DI PROVINSI NUSA TENGGARA BARAT
}

\section{HANDLINE PRODUCTIVITY IN WEST NUSA TENGGARA PROVINCE}

\author{
Ratih Purnama Sari ${ }^{1}$, Nora Akbarsyah ${ }^{2}$ \\ 1 Program Studi Perikanan Tangkap, Politeknik Kelautan dan Perikanan Dumai, \\ 2Fakultas Perikanan dan IImu Kelautan, Universitas Padjajaran, \\ "Korespondensi: ratihp.salim@gmail.com (RP Sari) \\ Diterima 2 Maret 2020 - Disetujui 25 Maret 2020
}

\begin{abstract}
ABSTRAK. Sebagian besar nelayan di Nusa Tenggara Barat (NTB) menggunakan pancing ulur (handline) sebagai alat tangkap (Santoso 2016). Jumlah alat tangkap ini mengalami peningkatan dari tahun 2008 hingga tahun 2012. Produksi perikanan pancing ulur juga menghasilkan lebih banyak hasil tangkapan dibandingkan dengan alat tangkap lain. Gejala penangkapan berlebih (over fishing) dapat diatasi dengan memanfaatkan sumberdaya perikanan yang berkelanjutan. Armada penangkapan ikan yang tersebar di beberapa lokasi perlu mengikuti ketersediaan stok ikan agar dapat diperoleh keuntungan secara ekonomi. Penelitian ini bertujuan untuk mengkaji dan membandingkan nilai produktivitas alat tangkap pancing ulur (hand line) yang digunakan di beberapa lokasi wilayah Nusa Tenggara Barat. Produktivitas yang diukur dalam penelitian ini adalah produktivitas alat tangkap pancing ulur. Hasil yang diperoleh menunjukkan bahwa peningkatan total hasil tangkapan dari tahun 2009 hingga 2010 adalah sebesar 22,62\% yang diikuti dengan peningkatan total trip penangkapan sebesar $30,57 \%$. Jumlah total trip penangkapan terus meningkat hingga tahun 2011 sedangkan total hasil tangkapan menurun menjadi sebesar $27,32 \%$ dari tahun 2010 . Tren catch per unit effort (CPUE) untuk mengalami peningkatan $65,59 \%$ dari tahun 2010 ke 2011 dan mengalami penurunan sebesar $83,84 \%$ dari tahun 2011 sampai dengan tahun 2013. Nelayan meningkatkan jumlah armada penangkapan dengan harapan untuk meningkatkan jumlah hasil tangkapan, tetapi pada hasil nya dititik tertentu penambahan alat tangkap tidak sebanding dengan jumlah hasil tangkapan yang diterima.
\end{abstract}

KATA KUNCI: Produktivitas, pancing ulur, produktivitas pancing ulur, Nusa Tenggara Barat

ABSTRACT. Many of fishermen in West Nusa Tenggara used hand line as their fishing gear (Santoso 2016). The amount of this fishing gear increased from year 2008 unti 2012. Fish production by hand line also produce more catches than other fishing gear. Overfishing symptoms could be overcome by utilize the sustainability fisheries resources. Catch fishing fleet distribution in several location should be appropriated with fish stock availability in order to obtain economics benefits. This study aimed to examine and compare hand line productivity which was used in several regions of West Nusa Tenggara. This study measured and analysed hand line productivity. The result of this study was shown that the increasing of total catches from year 2009 until 2010 was about $22,62 \%$ that was followed by the increasing of total trips was about $30,57 \%$. The amount of total trips continued to increased until year 2011 whereas the total catches decreased into 27,32\% from year 2010. Trend of catch per unit effort increased into 65,59\% from year 2010 until 2011 and decreased into 83,84\% from year 2011 until 2013. Fishermen increased number of fishing fleets with hope that they also could increase number of catches. But at a certain point, adding fishing gear (hand line) was not proportional with number of catches production.

KEYWORDS: Productivity, hand line, handline productivity, West Nusa Tenggara 


\section{Pendahuluan}

Provinsi Nusa Tenggara Barat (NTB) terdiri dari dua pulau yaitu Pulau Lombok dan Pulau Sumbawa. Pulau Lombok memiliki lima Kabupaten, yaitu Kabupaten Lombok Timur, Kabupaten Lombok Barat, Kabupaten Lombok Utara, Kabupaten Lombok Tengah, dan Kota Mataram. Pulau Sumbawa juga memiliki lima Kabupaten/Kota, yaitu Kabupaten Dompu, Kabupaten Sumbawa Barat, Kota Bima, dan Kabupaten Sumbawa. Nelayan di Provinsi Nusa Tenggara Barat masih dikatakan sebagai nelayan skala kecil karena masih menggunakan berbagai jenis alat tangkap (multi gear) serta menangkap berbagai jenis hasil tangkapan (multi species).

Alat tangkap yang banyak digunakan oleh nelayan di Provinsi Nusa Tenggara Barat adalah pancing ulur (hand line) sesuai hasil penelitian Santoso (2016). Jumlah alat tangkap ini selalu meningkat dari Tahun 2008-2012. Produksi perikanan oleh unit penangkapan pancing ulur juga menghasilkan tangkapan yang lebih besar dibandingkan alat tangkap lain. Pancing ulur biasanya digunakan untuk menangkap ikan-ikan demersal (ikan karang), seperti ikan kerapu dan ikan kakap (Santoso, 2016). Namun alat tangkap ini juga digunakan oleh nelayan Provinsi Nusa Tenggara Barat untuk menangkap ikan tuna sirip kuning (Wildan, 2014). Komoditas ini memiliki nilai ekonomis tinggi karena harga jualnya yang tinggi sehingga menjadi komoditas yang penting di Indonesia.

Kebutuhan akan pemenuhan ekonomi daerah, peningkatan kesejahteraan nelayan, dan perluasan kesempatan kerja merupakan harapan dari pembangunan subsektor perikanan tangkap. Tingginya permintaan berbagai jenis ikan meningkatkan upaya penangkapan dan akan berdampak pada terjadinya gejala penangkapan berlebih (over fishing) dalam waktu yang panjang jika tidak dikelola dengan baik. Upaya penangkapan yang tidak dikontrol dengan baik maka produktivitas perikanan tangkap akan mengalami penurunan produktivitas (Smith \& Link, 2005).

Gejala penangkapan berlebih ini dapat diatasi dengan melakukan upaya pengelolaan sumberdaya ikan agar dapat diperbaharui. Agar kegiatan pengelolaan dan pemanfaatan sumberdaya ikan yang berkelanjutan dapat dilakukan, maka produktivitas penangkapan juga perlu diupayakan. Armada penangkapan yang terdistribusi di berbagai lokasi penangkapan perlu mengikuti ketersediaan stok ikan agar dapat diperoleh keuntungan secara ekonomi. Penelitian ini bertujuan untuk mengkaji dan membandingkan nilai produktivitas alat tangkap pancing ulur (hand line) yang digunakan di beberapa lokasi wilayah Nusa Tenggara Barat. Data yang digunakan adalah data tahun 2009, 2010, 2011, dan tahun 2013 agar trend produktivitas alat tangkap dapat dilihat. Penelitian ini bermanfaat sebagai informasi awal untuk pemanfaatan dan pengelolaan sumberdaya ikan.

\section{Bahan dan Metode}

Data dikumpulkan dari kabupaten yang memiliki unit penangkapan pancing ulur yang paling dominan di Provinsi NTB, seperti Kabupaten Lombok Barat, Kabupaten Sumbawa, Kabupaten Sumbawa Barat, Kabupaten Lombok Timur, Kabupaten Lombok Utara, dan Kabupaten Bima. Data yang dikumpulkan adalah data sekunder berupa produksi hasil tangkapan dan jumlah trip unit penangkapan pancing ulur tahun 2009, 2010, 2011, dan 2013. Data ini diperoleh dari data statistik Dinas Kelautan dan Perikanan Provinsi Nusa Tenggara Barat. Jumlah Unit Penangkapan Pancing Ulur di Provinsi Nusa Tenggara Barat dapat dilihat pada Gambar 1. 


\section{JUMLAH UNIT PENANGKAPAN PANCING ULUR PROVINSI \\ NTB}

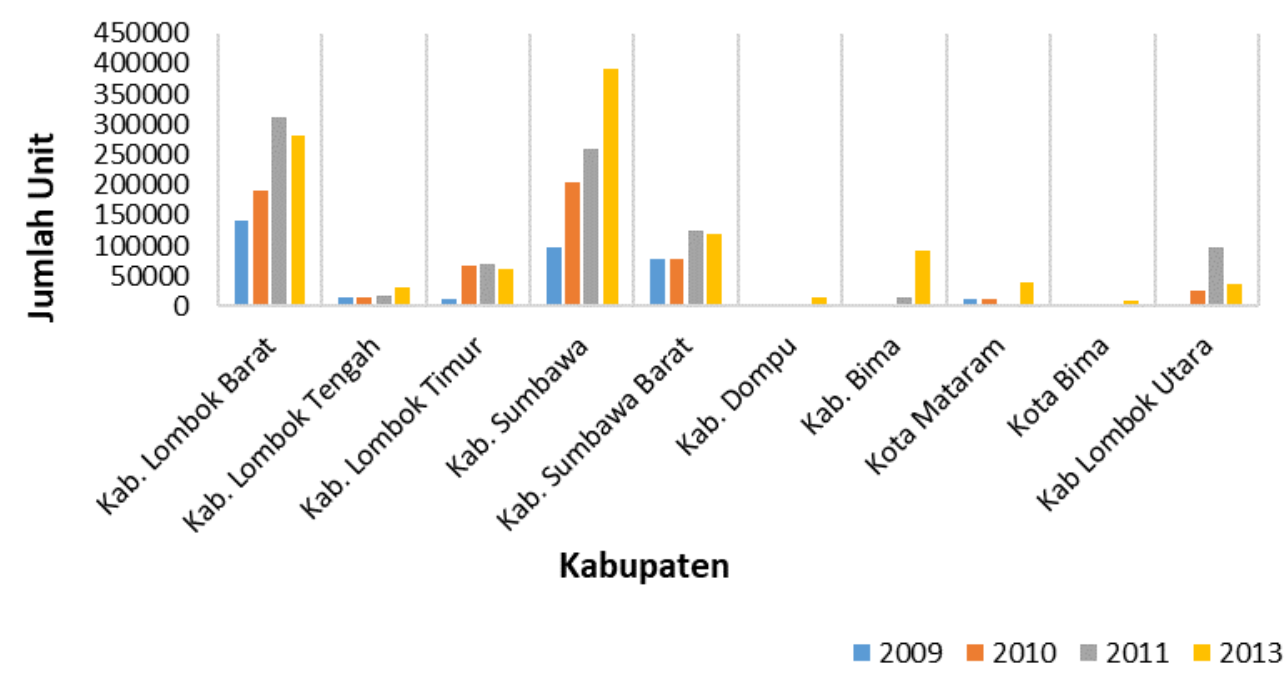

\section{Gambar 1. Jumlah Unit Penangkapan Pancing Ulur di Provinsi Nusa Tenggara Barat}

Produktivitas yang diukur dalam penelitian ini adalah produktivitas alat tangkap pancing ulur. Produksi penangkapan ditentukan berdasarkan volume hasil tangkapan ikan (Ton) dan jumlah trip unit pancing ulur, yang dapat dijelaskan dengan persamaan:

$$
\text { Produktivitas }=\frac{\text { Produksi hasil tangkapan pancing ulur (Ton) }}{\text { Jumlah trip penangkapan }}
$$

Menurut Keputusan Menteri Kelautan dan Perikanan Nomor 38 Tahun 2003, produktivitas didefinisikan sebagai tingkat kemampuan kapal perikanan untuk memperoleh hasil tangkapan ikan dalam satu tahun.

\section{Hasil dan Pembahasan}

\subsection{Tren Hasil Tangkapan Tahunan}

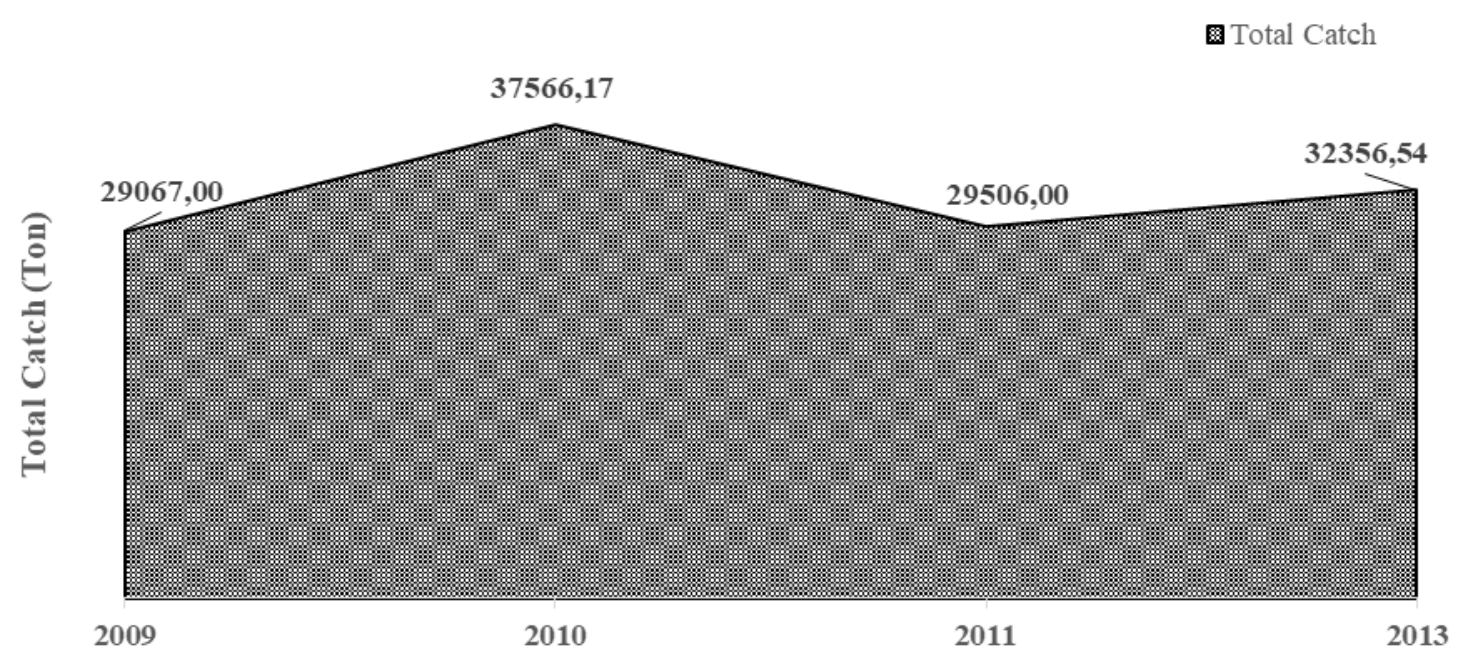



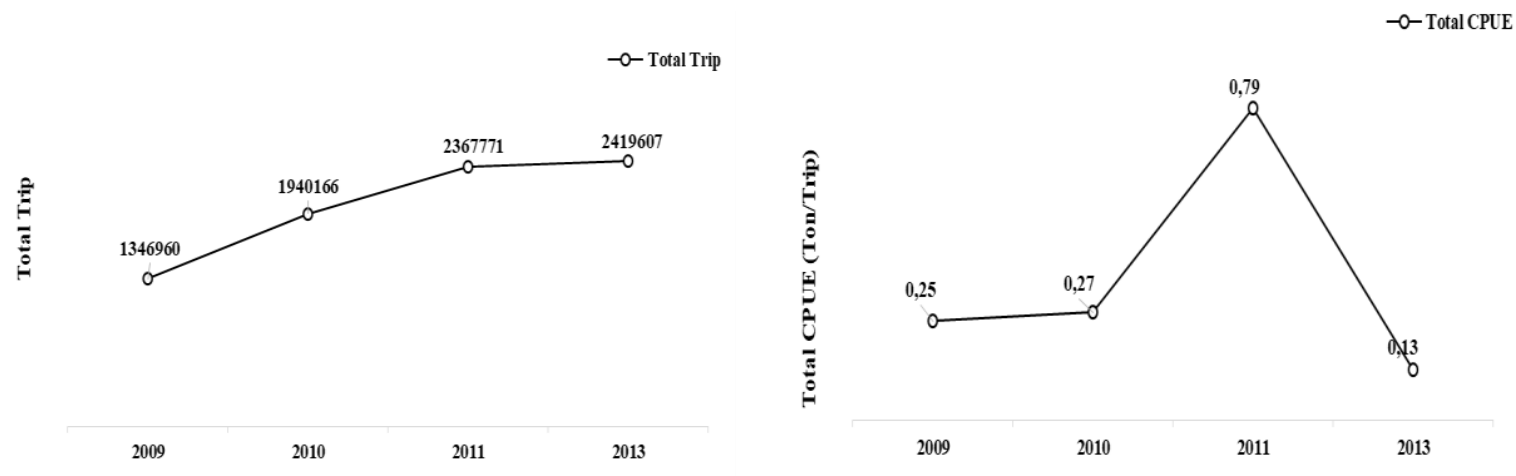

Gambar 2. Perkembangan Rata-rata Nominal Total Hasil Tangkapan, Trip, dan CPUE Tahunan di Nusa Tenggara Barat

Hasil tangkapan pancing ulur pada seluruh daerah Nusa Tenggara Barat mempunyai angka paling tinggi pada tahun 2010 dan paling rendah tahun 2011. Sedangkan untuk jumlah trip cenderung mengalami peningkatan dari tahun ke tahun. Untuk jumlah CPUE paling tinggi ada pada tahun 2011, dan mengalami penurunan secara drastis pada tahun 2013.
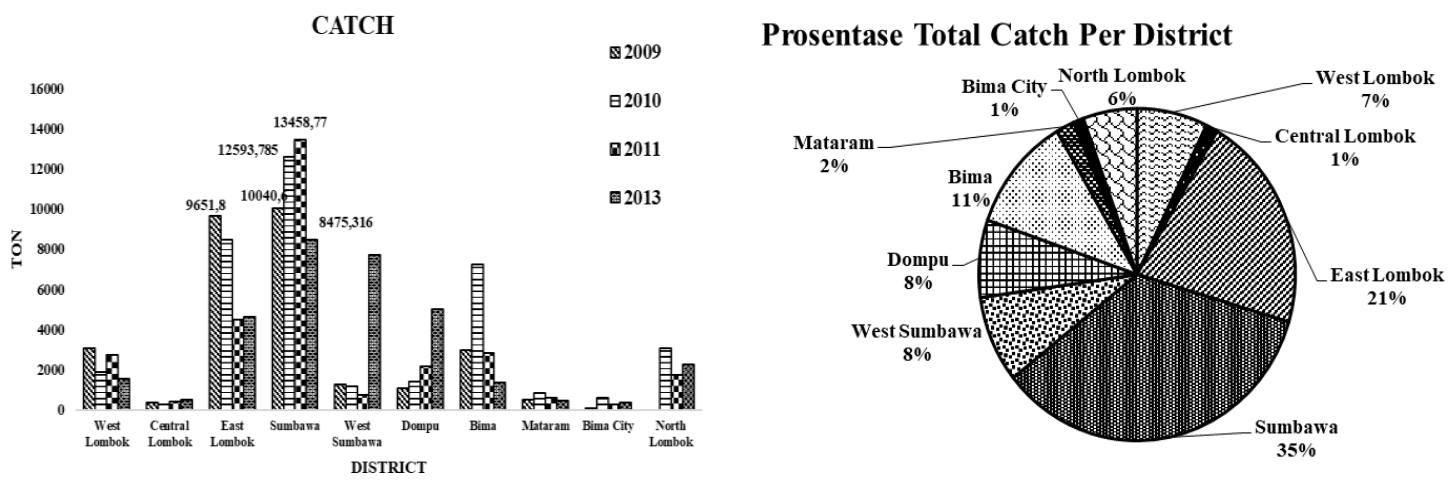

\section{Gambar 3. Perkembangan Total Hasil Tangkapan Tahunan per-Kabupaten di Nusa Tenggara Barat}

Total hasil tangkapan tertinggi dari sepuluh kabupaten yang ada di provinsi Nusa Tenggara Barat yaitu kabupaten Sumbawa dengan besaran 35\% dari seluruh total tangkapan. Kabupaten Lombok Timur mempunyai jumlah hasil tangkapan tertinggi kedua yaitu sebesar $21 \%$. Sedangkan, hasil tangkapan terendah yaitu dari kabupaten Lombok Tengah dan kota Bima masing-masing menyumbang $1 \%$ dari seluruh total tangkapan. Hasil tangkapan pancing ulur dari kabupaten Sumbawa tertinggi pada tahun 2011 mencapai 13.458 ton. Sedangkan tangkapan terendah pada tahun 2013 yaitu 8.475 Ton. Delapan kabupaten lain mempunyai hasil tangkapan yang tidak lebih dari $11 \%$ dari seluruh hasil tangkapan selama 5 tahun. Pada beberapa kabupaten seperti Sumbawa Barat dan Dompu mengalami peningkatan yang banyak pada tahun 2011-2013. Kabupaten Sumbawa Barat mengalami peningkatan hasil tangkapan sebesar 90,54\% dan Kabupaten Dompu meningkat sebesar $56,17 \%$ sepanjang tahun $2011-2013$. 


\subsection{Perkembangan Jumlah Trip Tahunan}
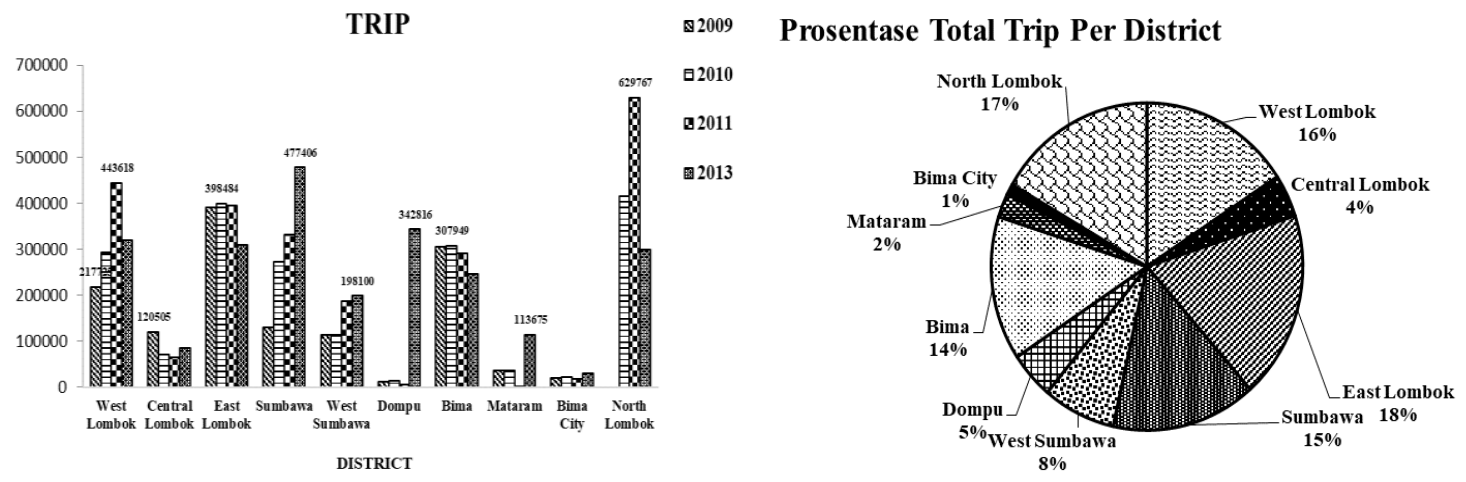

\section{Gambar 4. Perkembangan Rata-Rata Total Trip Penangkapan Ikan Tahunan di Nusa Tenggara Barat}

Jumlah trip pada kabupaten Lombok Barat, Sumbawa, Dompu, Mataram, dan Kota Bima cenderung mengalami peningkatan selama tahun 2009-2013. Adapun Kabupaten Lombok Timur, Kabupaten Bima, dan Lombok Utara berfluktuasi atau cenderung berkurang. Jumlah Kabupaten Lombok Barat, Lombok Timur dan Lombok Utara secara berurutan mengalami penurunan sebesar 28\%, 21,78\% dan 52,61\% pada tahun 2011-2013. Sedangkan Kabupaten Sumbawa, Dompu, dan Mataram secara berurutan mengalami peningkatan sebesar 30,37\%, 98,14\%, dan 98,47\%. Jumlah trip terbanyak sepanjang tahun 2009 - 2013 yaitu kabupaten Lombok Timur (18\%), Sumbawa (15\%), Bima (14\%), Lombok Utara (17\%), dan Lombok Barat (16\%). Adapun jumlah trip kabupaten lainnya tidak lebih dari $10 \%$ dari keseluruhan trip yang dilakukan di Provinsi Nusa Tenggara Barat.

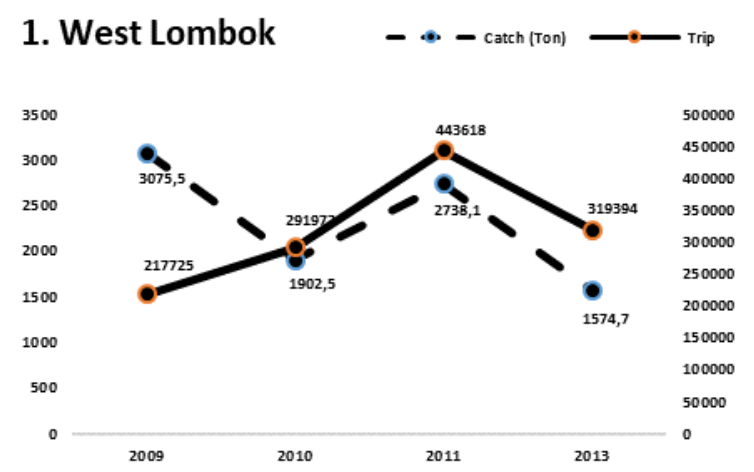

\section{Central Lombok}
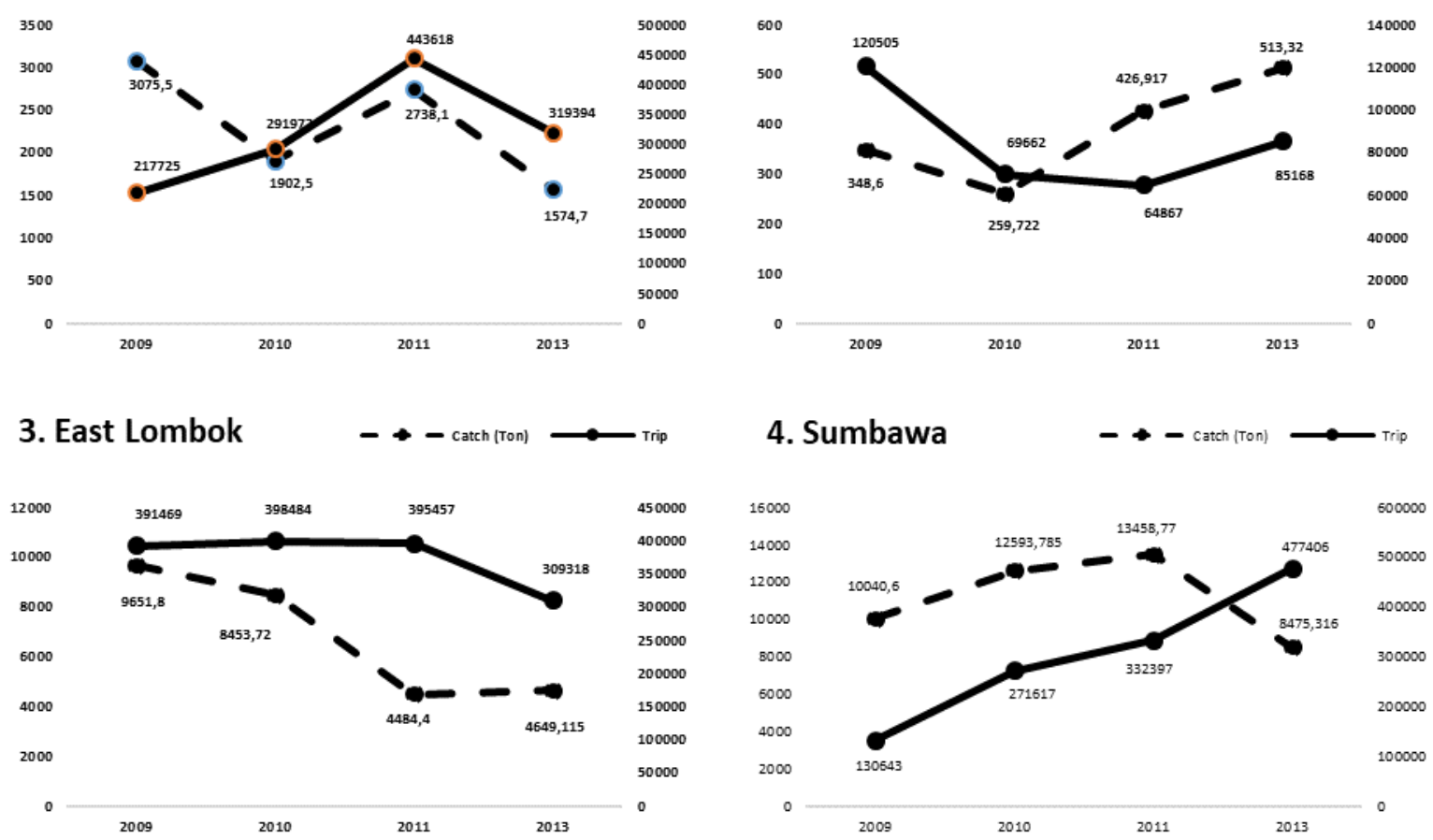

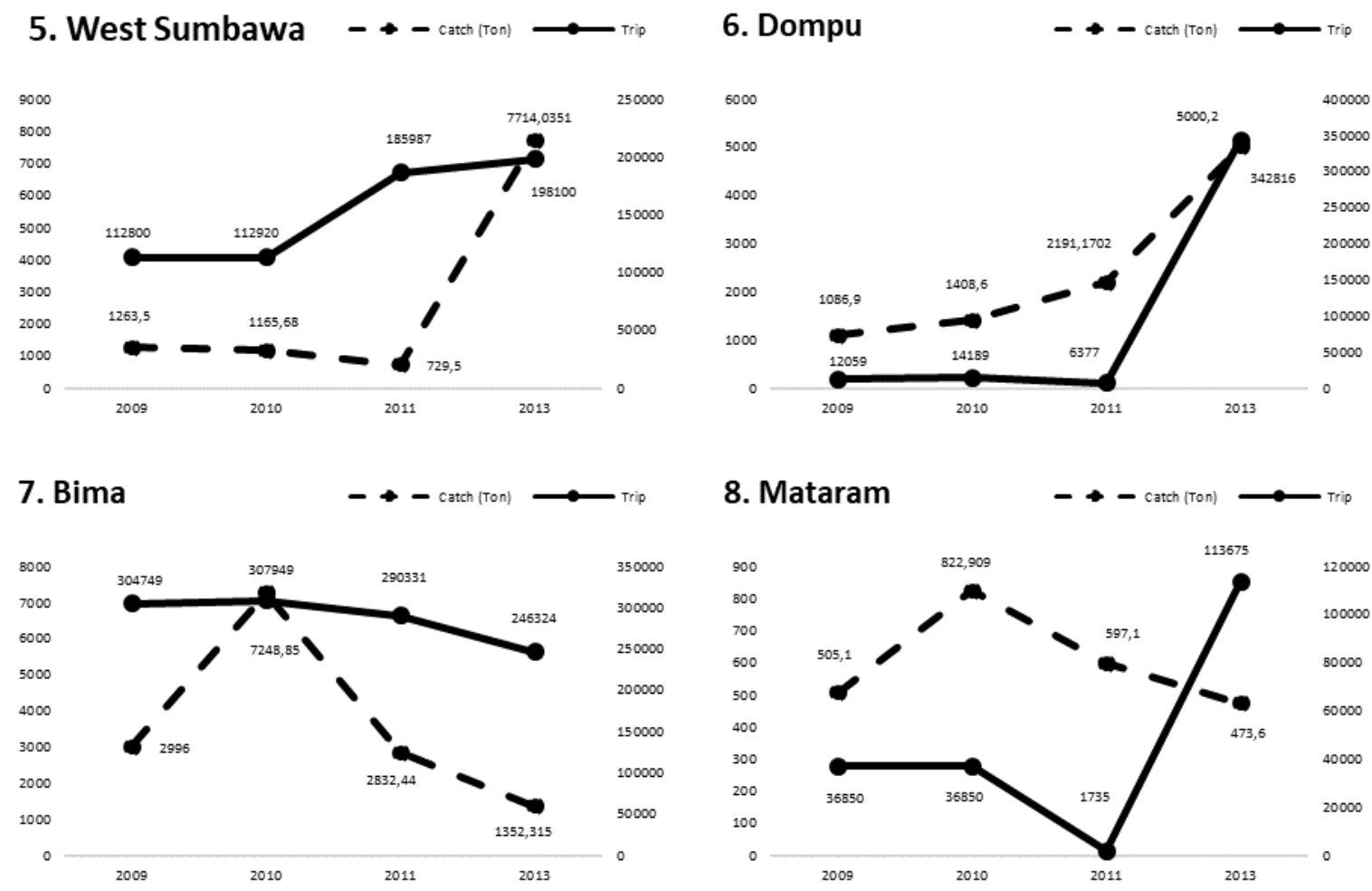

\section{Bima City}

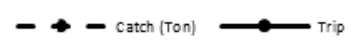

10. Lombok North
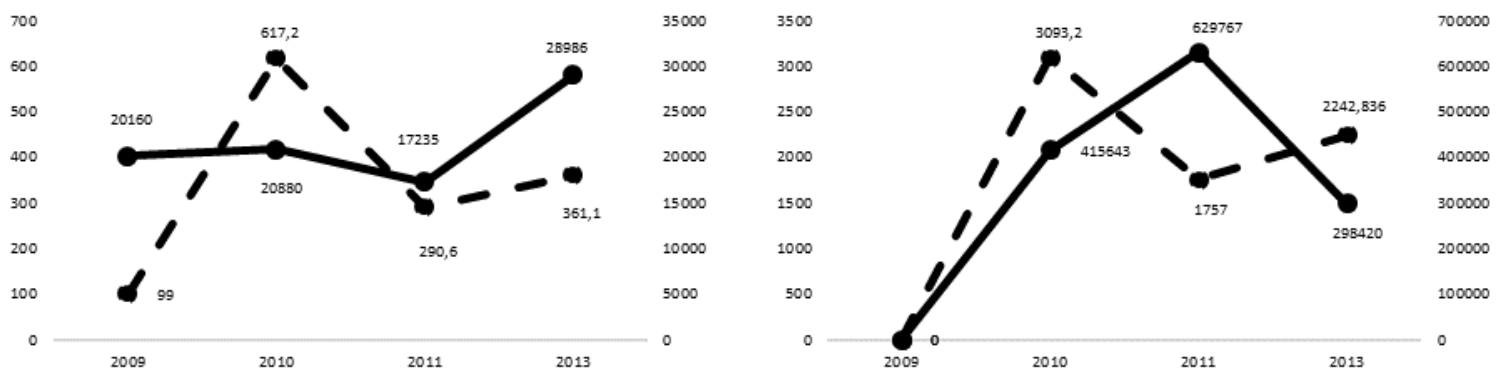

Gambar 5. Perkembangan Total Nominal CPUE Tahunan per-Kabupaten di Provinsi Nusa Tenggara Barat

Fluktuasi hasil tangkapan pancing ulur setiap tahun selama lima tahun (2009-2013) menunjukkan tren yang berbeda setiap tempat. Kabupaten Lombok Barat, Lombok Timur, dan Bima mempunyai kecenderungan meuurun tiap tahunnya baik hasil tangkapan maupun jumlah trip penangkapan. Berbeda dengan kabupaten Sumbawa barat dan Dompu dimana Hasil tangkapan dan jumlah trip meningkat. Sedangkan untuk kabupaten Lombok tengah, mengalami kenaikan jumlah hasil tangkapan diiringi dengan turunnya jumlah trip penangkapan. Kabupaten Mataram sebaliknya, mengalami penurunan pada jumlah hasil tangkapan sedangkan jumlah trip penangkapan meningkat. Adapun hasil tangkapan dan jumlah trip kabupaten Sumbawa, Kota Bima, dan Lombok Utara berfluktuasi pada setiap tahunnya. 


\subsection{Perkembangan CPUE Tahunan}

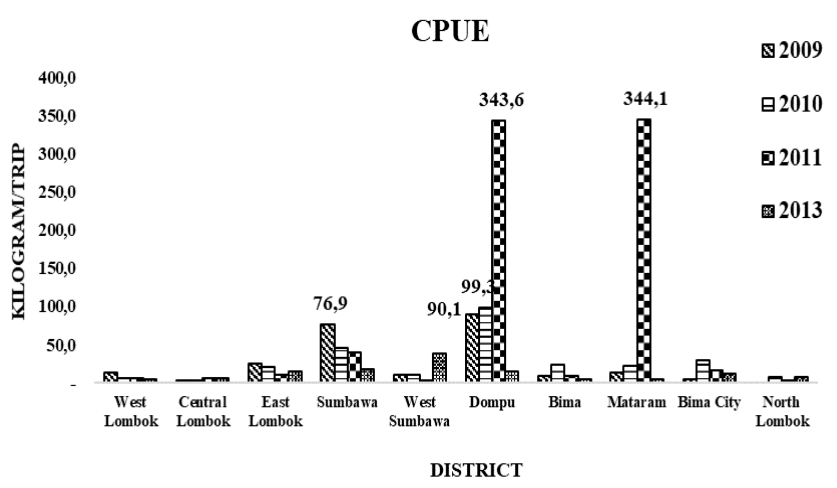

Gambar 6. Perkembangan Total Nominal CPUE Tahunan di Provinsi Nusa Tenggara Barat

Total CPUE paling tinggi adalah Kabupaten Dompu dan Mataram yaitu 343,6 kg/trip dan 344,1 $\mathrm{kg} /$ trip pada tahun 2011. Pada tahun sebelumnya (2009-2010), total CPUE pada kabupaten Dompu dan Mataram mengalami peningkatan. Nilai tersebut mengalami penurunan yang sangat drastis pada tahun 2013. Sedangkan pada delapan kabupaten lainnya total CPUE cenderung mengalami penurunan selama tahun 2009-2013.

Peningkatan total hasil tangkapan pada tahun $2009-2010$ sebesar $22,62 \%$ diiringi dengan peningkatan total trip sebesar 30,57\%. Jumlah total trip terus meningkat sampai dengan tahun 2011 tetapi total tangkapan menurun sampai dengan $27,32 \%$ dari tahun 2010 . Tren catch per unit effort (CPUE) untuk mengalami peningkatan 65,59\% dari tahun 2010 ke 2011 dan mengalami penurunan sebesar $83,84 \%$ dari tahun 2011 sampai dengan tahun 2013. Hal ini mungkin saja terjadi karena pengaruh tingkat efisiensi operasi alat tangkap (Mayu et al., 2018) yang salah satunya berupa taktik penangkapan (Budiarti et al., 2015), factor lingkungan seperti ketepatan daerah penangkapan (Masturah et al., 2014), dan kondisi oseanografi (Gaol \& Sadhotomo, 2007). Kelimpahan ikan dalam suatu perairan tidak bisa lepas dari keadaan parameter oseanografi (seperti suhu, salinitas, gelombang, pH, arus, dan Klorofil-a) (Arifin, 2014). Parameter tersebut berpengaruh selain dalam penyebaran ikan, tetapi juga sebagai petunjuk migrasi ikan, tingkah laku schooling, pemijahan, dan ketersediaan makanan di perairan (Setyohadi, 2011). Selain itu, meningkatnya jumlah trip (upaya penangkapan) dari tahun ke tahun dikhawatirkan menyebabkan terkurasnya sumberdaya ikan (Nababan \& Sari, 2007; Purwanto \& Nugroho, 2011). Hal ini disebabkan oleh cara eksploitasi sumbedaya ikan yang bersifat open access. Nelayan meningkatkan jumlah armada penangkapan dengan harapan untuk meningkatkan jumlah hasil tangkapan, tetapi pada hasil nya di titik tertentu penambahan input (alat tangkap) tidak sebanding dengan jumlah output (hasil tangkapan) yang diterima (Dafiq et al., 2019; Zulbainarni, 2013).

\section{Kesimpulan}

Kegiatan penangkapan ikan di wilayah Nusa Tenggara Barat tertinggi terjadi pada tahun 2010 dan terendah terjadi pada tahun 20111. Sedangkan jumlah trip penangkapan ikan cenderung meningkat setiap tahun. Jumlah Catch per Unit Effort (CPUE) terjadi pada tahun 2011 dan menurun secara signifikan pada tahun 2013. Jumlah kegiatan penangkapan (jumlah trip) di wilayah Lombok Barat, Sumbawa, Dompu, Mataram, dan Kota Bima cenderung meningkat sepanjang tahun 2009 hingga 2013. Wilayah Lombok Timur, Bima, dan Lombok Utara berfluktuatif atau cenderung menurun. Total CPUE paling tinggi terdapat di Kabupaten Dompu dan Mataram pada tahun 2011. Sedangkan pada delapan kabupaten lainnya total CPUE cenderung mengalami penurunan dari tahun 2009 hingga 2013. Naik turunnya nilai CPUE setiap tahun dapat terjadi karena pengaruh tingkat efisiensi operasi 
alat tangkap yang salah satunya berupa taktik penangkapan, faktor lingkungan seperti ketepatan daerah penangkapan, dan kondisi oseanografi.

\section{DAFTAR PUSTAKA}

Keputusan Menteri Kelautan dan Perikanan Nomor 38. (2003). Produktivitas Kapal Penangkap Ikan. Depertemen Kelautan dan Perikanan Republik Indonesia.

Arifin, Z. (2014). Arah dan Rencana Riset Oseanografi pada Samidera Hindia 2015-2020. Pusat Penelitian LIPI- Oseanografi. Jakarta: 64 hal.

Budiarti, T. W., Wiyono, E, S., \& Zulbainarni, N. (2015). Produksi Optimal Pukat Cincin di Pelabuhan Perikanan Nusantara Pemangkat, Kalimantan Barat. J. Lit. Perikan. Ind. 21(1): 37-44.

Dafiq, A. H. D., Anna, Z., Rizal, A., \& Suryana, A. A. H. (2019). Analisis Bioekonomi Sumberdaya Ikan Kakap Merah (Lutjanus malabaricus) di Perairan Kabupaten Indramayu Jawa Barat. Jurnal Perikanan dan Kelautan. X(1): 8-19.

Gaol, J. L., \& Sadhotomo, B. (2007). Karakteristik dan Variabilitas parameter Oseanografi laut Jawa hubungannya dengan Distribusi hasil Tangkapan Ikan. Jurnal Penelitian Perikanan Indonesia. 13 (3): 1-12.

Masturah, H., Hutabarat, S., \& Hartoko, A. (2014). Analisa Variabel Oseanografi Data Modis Terhadap Sebaran Temporal Tenggiri (Scomberomous commersoni, Lacepede 1800) di Sekitar Selat Karimata. Diponegoro Journal of Maquares: Management of Aquatic Resources. 3(2): 11-19.

Mayu, D. H., Kurniawan., \& Arief, F. (2018). Analisis Potensi dan Tingkat Pemanfaatan Sumberdaya Ikan di Perairan Kabupaten Bangka Selatan. Jurnal Perikanan Tangkap. 2 (1):30-41.

Nababan, B. O., \& Sari, Y. D. (2007). Optimasi Pemanfaatan Sumberdaya Ikan Karang Hidup Konsumsi (Life Reef Fish for Food/LRFF) di Perairan Kepualauan Spermonde, Sulawesi Selatan. J Kebijakan dan Riset Sosek KP. 2(1): 1-17.

Purwanto, D., \& Nugroho. (2011). Daya Tangkap Kapal Pukat Cincin dan Upaya Penangkapan Pada Perikanan Pelagis Kecil di Laut Jawa. J.Lit. Perikan. Ind. 17(1): 23-30.

Santoso, D. (2016). Potensi Lestari dan Status Pemanfaatan Ikan Kakap Merah dan Ikan Kerapu di Selat Alas Provinsi Nusa Tenggara Barat. Jurnal Biologi Tropis. 16(1): $15-24$

Setyohadi, D. (2011). Pola Distribusi Suhu Permukaan laut dihubungkan dengan Kepadatan dan Sebaran Ikan lemuru (Sardinella lemuru) Hasil Tangkapan Purse Seine di Selat Bali. J-PAL. 1(2): 72-78.

Smith, T. D., \& Link, J. S. (2005). Autopsy Your Dead and Living: a Proposal for Fisheries Science, Fisheries Management and Fisheries. Fish and Fisheries VI: 73-87.

Wildan., Momo., Kochen., Nanda, G., \& Juhri. (2014). Struktur Ukuran Ikan Tuna Sirip Kunig (Thunnus albacares) yang tertangkap di WPP 713 dan 573. Simposium Nasional Pengelolaan Tuna Berkelanjutan. Bali.

Zulbainarni, N. (2013). Pengelolaan Sumberdaya Perikanan Tangkap yang Berkeadilan dan Berkelanjutan dalam kaitannya dengan otonomi daerah. Prosiding Kongres ISEI XVIII Satu Dasa Warsa Implementasi Ekonomi Daerah: 289-314. 